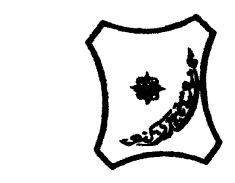

Bayero Journal of Pure and Applied Sciences, 1(1):53- 57

Received: September, 2008

Accepted: November, 2008

\title{
EFFECT OF NON-VOLATILE SOLUTE ON THE FREEZING POINT OF MALONIC ACID
}

\author{
*Uba, S. and Saeed, M. D. \\ Department of Pure and Industrial Chemistry, Bayero University, P. M. B 3011, Kano Nigeria. \\ *Correspondence Author: e-mail saniuba10@yahoo.com.
}

\begin{abstract}
The mixture of malonic acid and potassium chloride were obtained in various proportions. The freezing point of pure malonic acid was obtained in the range 134 and $135^{\circ} \mathrm{C}$ which is in agreement with the literature value of $135^{\circ} \mathrm{C}$. the freezing point of all the mixtures were below the literature value of $135^{\circ} \mathrm{C}$. the freezing point depression was found to be directly proportional to the amount of potassium chloride in the mixture.
\end{abstract}

Key word: malonic acid, potassium chloride, freezing point depression.

\section{INTRODUCTION}

Malonic acid is a white crystalline dicarboxylic acid with melting point range $134-135{ }^{\circ} \mathrm{C}$. It is solid at room temperature with density of $1,619 \mathrm{~g} / \mathrm{cm}^{3}$ and

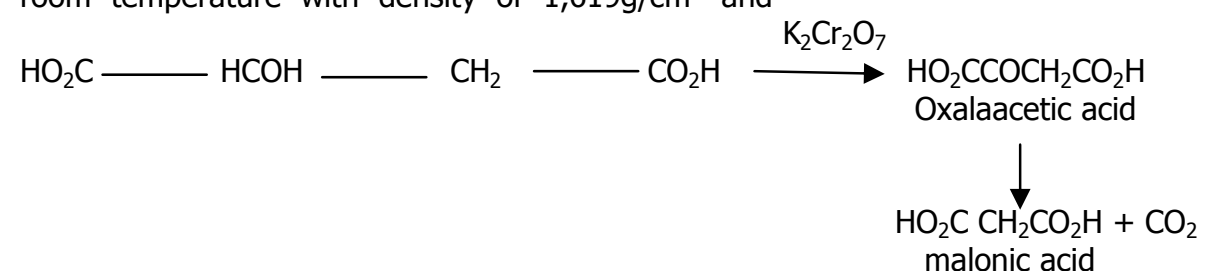

Malonic acid is also prepared by heating potassium chloroacetate with aqueous potassium cyanide and hydrolyzing the product. The IUPAC name of this organic is propanedioic acid (Hill, 1974).

$$
\mathrm{ClCH}_{2} \mathrm{CO}_{2} \mathrm{~K} \longrightarrow \mathrm{CH}_{2}(\mathrm{CN}) \mathrm{CO}_{2} \mathrm{~K} \longrightarrow \mathrm{CH}_{2}\left(\mathrm{CO}_{2} \mathrm{H}\right)_{2}
$$

To ascertain the purity of a given solid or liquid, its freezing point is normally measured. If the freezing point is below the recorded value in literature, then, an impurity may be present. However, if the value is as recorded in the literature, then the compound is pure (Atkins, 1997).

The freezing point depression depends on the number of moles of non-volatile solute (Alberty, 1979) and not on their nature or kind of solute (big, small, height, heavy, etc) (Michael, 1987).

According to Atkins and Clugston (1982), freezing point depression depends on the mole fraction of solute present and its measurement can be used to determine the molar mass of the solute. This technique is known as cryoscopy. Freezing point depression is related by $\Delta T=i K_{f} m$ where $K_{f}=$ Cryoscopic constant, $\mathrm{i}=$ Ionization factor which is 1 for non electrolyte. $m=$ molality of the solute, $\Delta T=$ Freezing point depression. Since there is ionization factor, $i$, in the freezing point depression relation, the depression will be greater if the solute is an electrolyte and vice versa.

There are several methods available for obtaining the freezing point curves. First and fore most, is a plot of temperature against time. In this case, the temperature at which the solid in first seen to melt and that at which the melting is complete is observed. Secondly, is the cooling curve plot, this shows the variation of temperature as the liquid cools until it has completely solidified.

The aim of this research therefore, were to determine the purity of the malonic acid as is one of the most important ingredients in the pharmaceutical industries (Finar, 1973) and to also to determine the effect of non-volatile solute on the freezing point of a solvent.

\section{MATERIALS AND METHODS \\ Quality Control}

All glass wares, plastic containers, crucibles, mortal and pestle were washed with liquid soap, rinsed with distilled water and then soaked in $10 \% \mathrm{HNO}_{3}$ solution for 24 hrs (Todorovi et a/2001). They were then washed with distilled water and dried in memmert drying oven at $80^{\circ} \mathrm{C}$ for

\section{Reagents}

Malonic acid, Potassium chloride. 


\section{Apparatus}

Test tubes, thermometer, stirrer, beaker, retort stand, test tube - holder, hot plate, Beckmann's freezing point apparatus.

\section{Experimental}

Five different mixtures of malonic acid were prepared with potassium chloride by placing $5 \mathrm{~g}$ of malonic acid each in six different clear test-tube. $0.5 \mathrm{~g}, 0.7 \mathrm{~g}, 0.9 \mathrm{~g}$, $1.1 \mathrm{~g}$ and $1.3 \mathrm{~g}$ of potassium chloride were added to the five test tubes containing the acid. The freezing points of theses mixtures were determined in Beckmann's freezing point apparatus as follows.

$5 \mathrm{~g}$ of malonic acid was heated to meet on a hot plates and then cooled in the Beckmann's freezing point apparatus containing the crushed ice. The temperature readings were taken at an interval of one minute until all the malonic acid was solidified.

The same procedure was repeated for other sample mixtures and tables for six cooling curves were obtained. Until results for six cooling curves was obtained (Figures $1-6$ ).

\section{RESULTS AND DISCUSSION}

The graphical representation of the variation in temperature with time is referred to as cooling curve. These are presented in Figures I to VI. The curve usually has three important features; the linear variation of temperature with time, the region where the temperature remains constant for a time values and the region where there is sharp reduction.

Extrapolation of the point where the temperature remains constant o the temperature axis give eutectic temperature. The eutectic temperature is the temperature corresponding to this lowest freezing point at a single temperature without change of composition. The points of constant temperature for a set of time are the freezing point temperature $T_{f}$.

From figure 1 , it can be observed that the transition temperatures of melting $5 \mathrm{~g}$ malonic acid ranges between 134 and $135^{\circ} \mathrm{C}$ beyond these values, the temperature variation with time correspond to the freezing point. As can be seen from figures $1-6$, freezing point depression depends on the number of solute present i.e. potassium chloride.

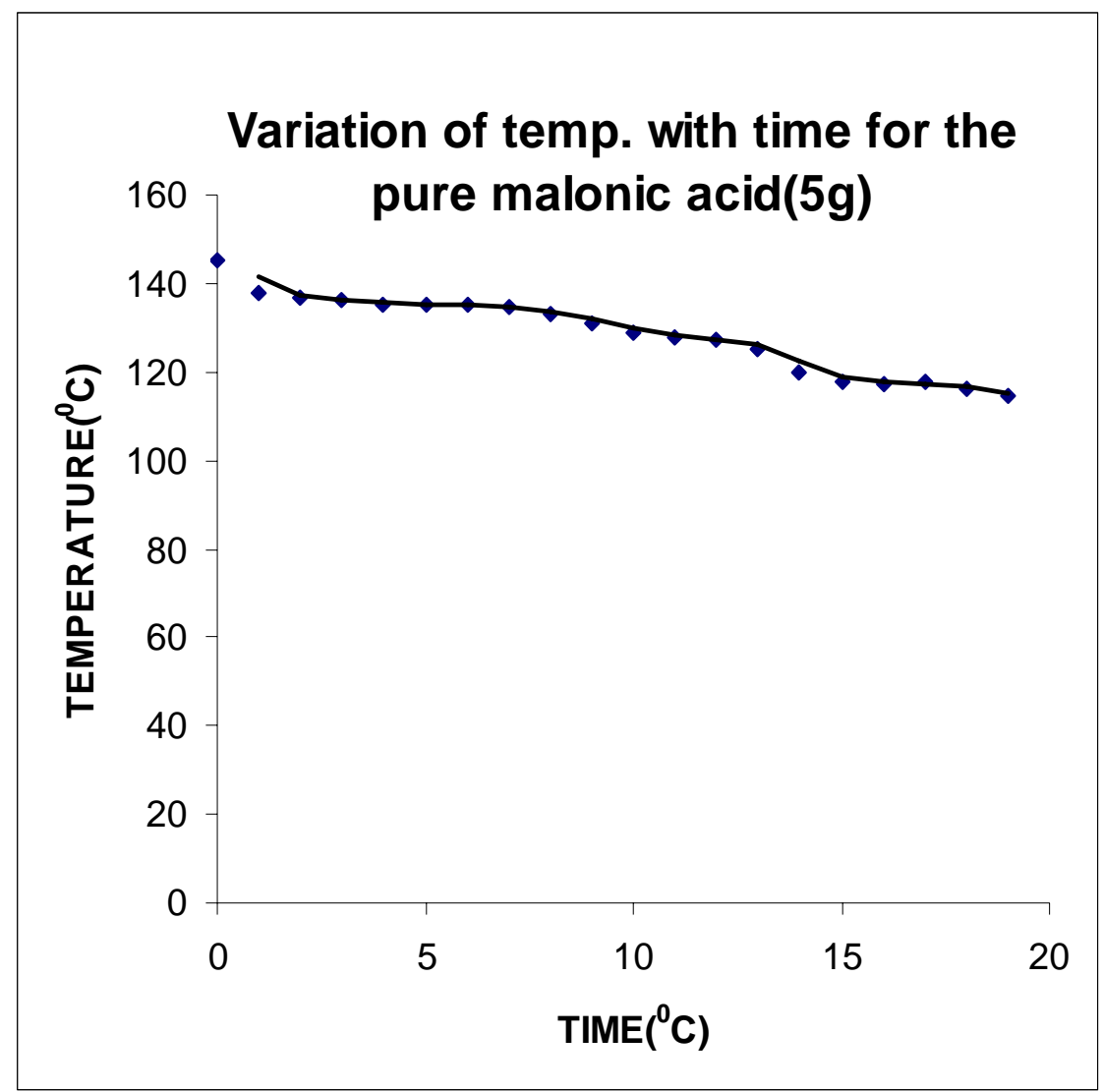

Figure 1: Variation of Temperature with Time for the Pure Malonic Acig (5g) 


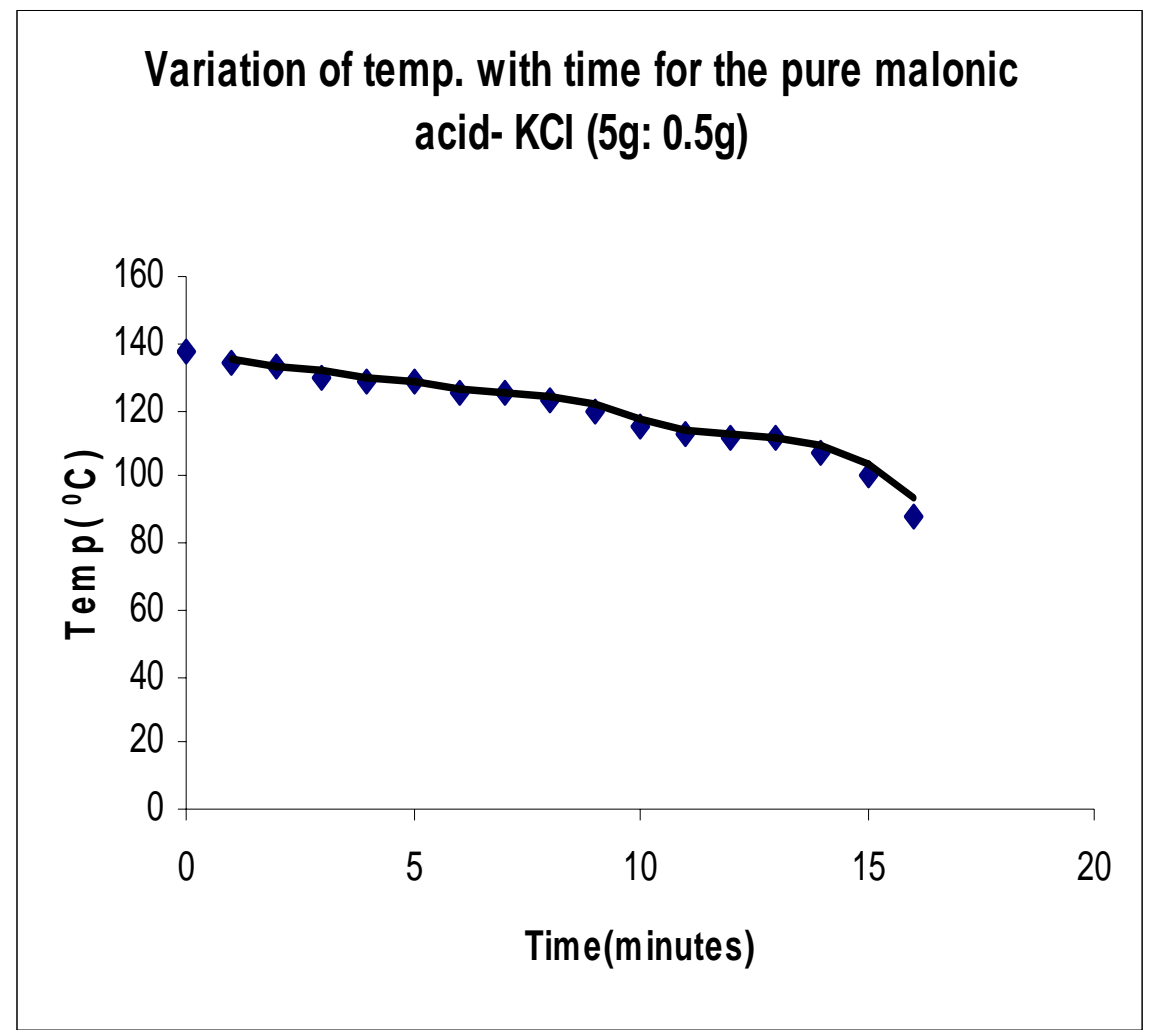

Figure 2: Variation of Temperature with Time for the Pure Malonic Acig - KCl (5g:0.5g)

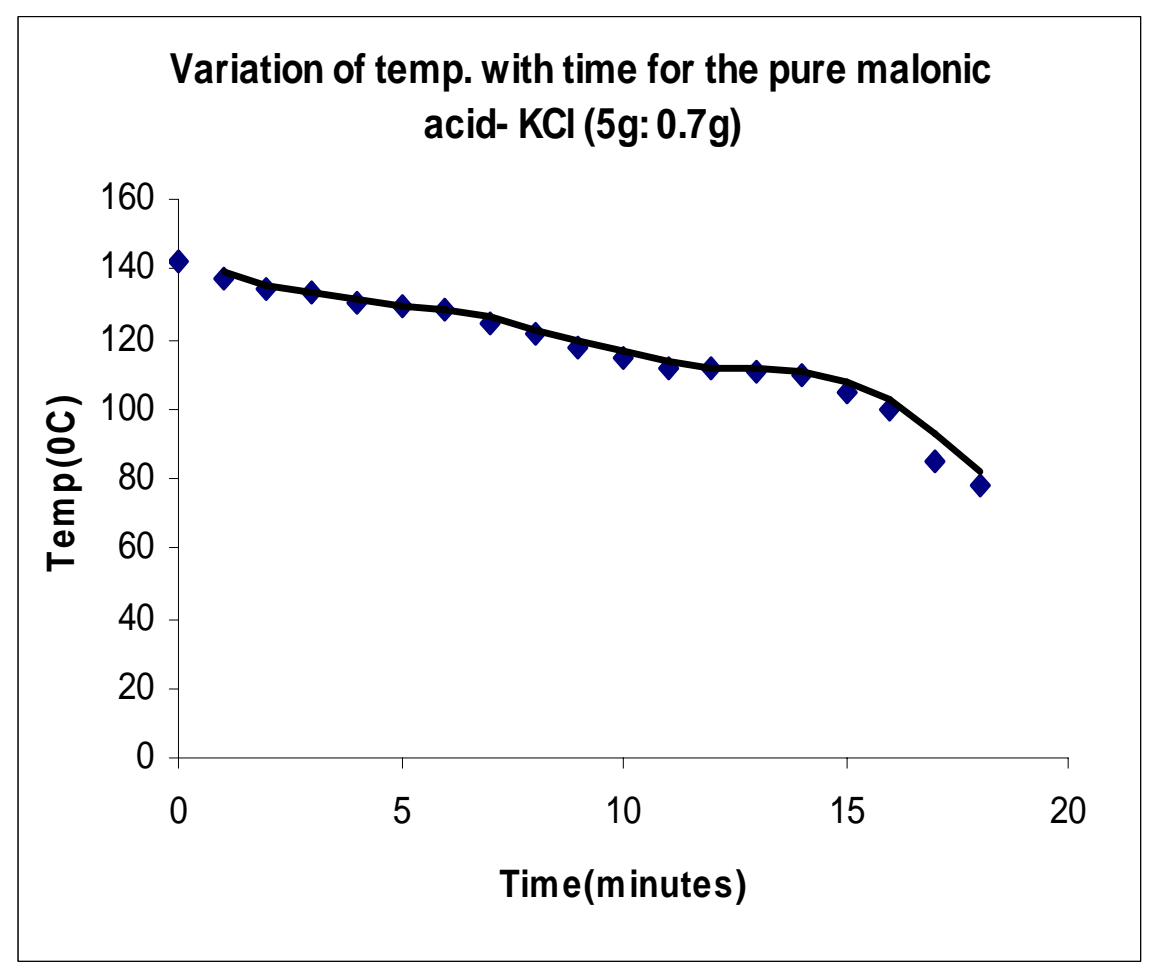

Figure 3: Variation of Temperature with Time for the Pure Malonic Acig - $\mathrm{KCl}(5 \mathrm{~g}: 0.7 \mathrm{~g})$ 


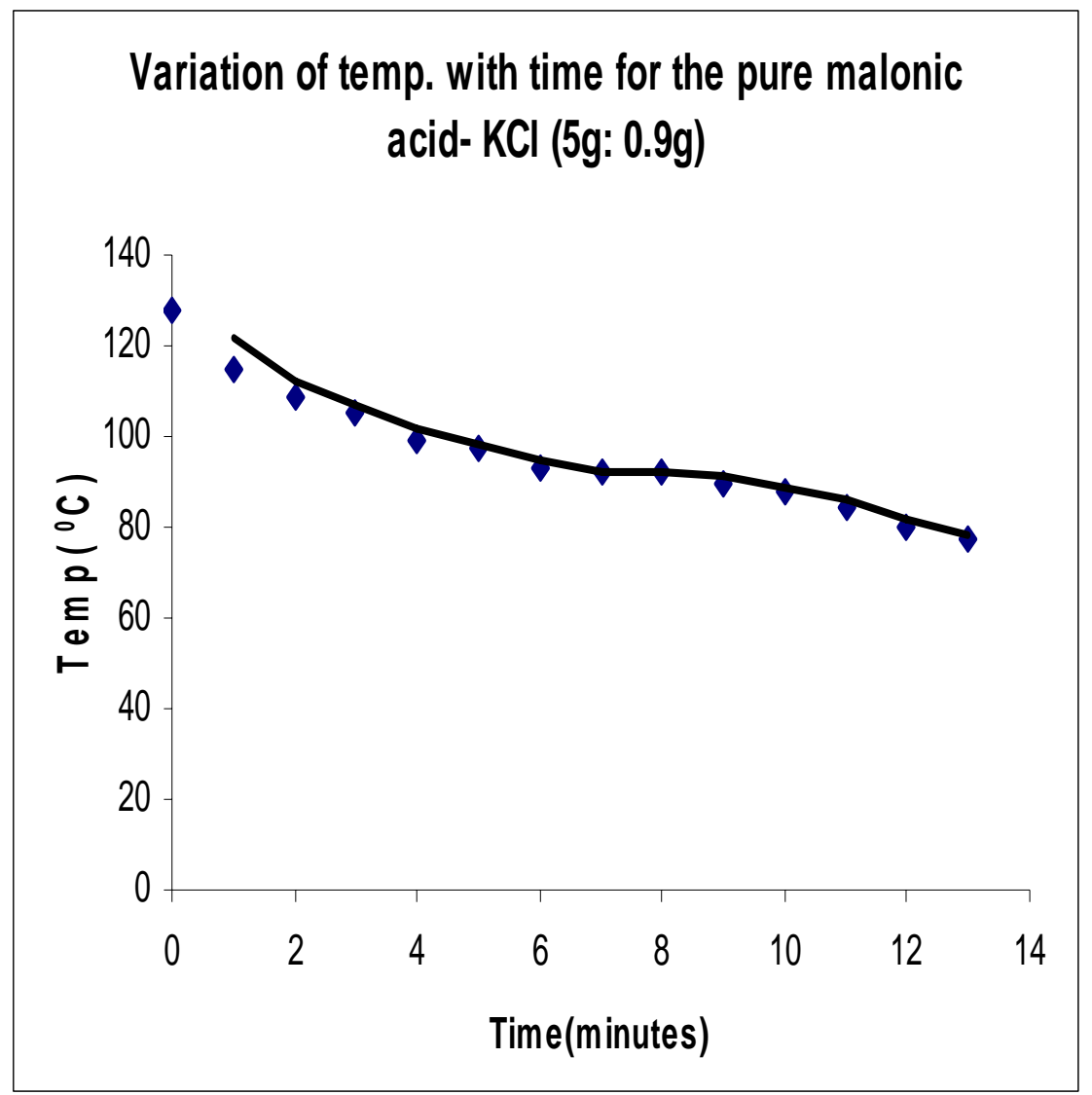

Figure 4: Variation of Temperature with Time for the Pure Malonic Acig - $\mathrm{KCl}(5 \mathrm{~g}: 0.9 \mathrm{~g})$

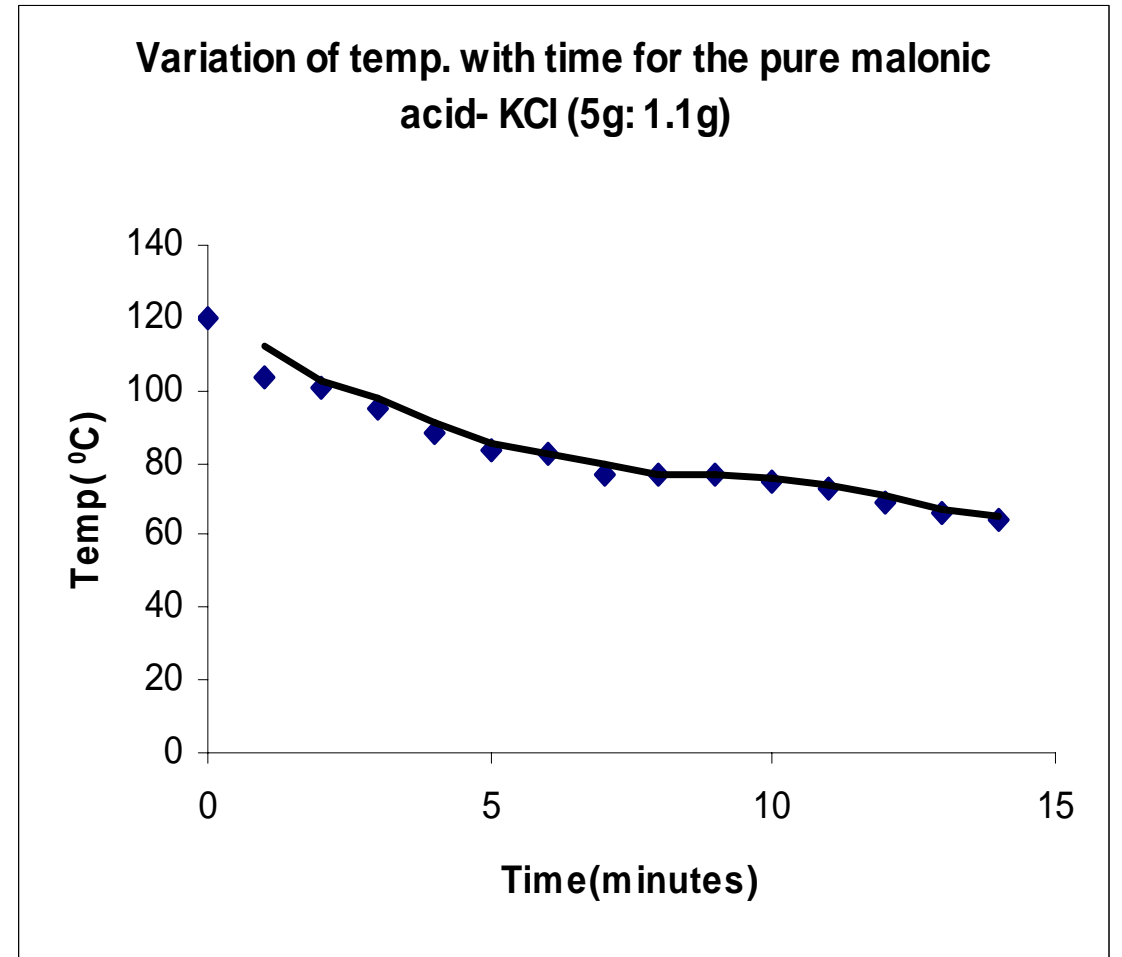

Figure 5: Variation of Temperature with Time for the Pure Malonic Acig - KCl (5g:1.1g) 


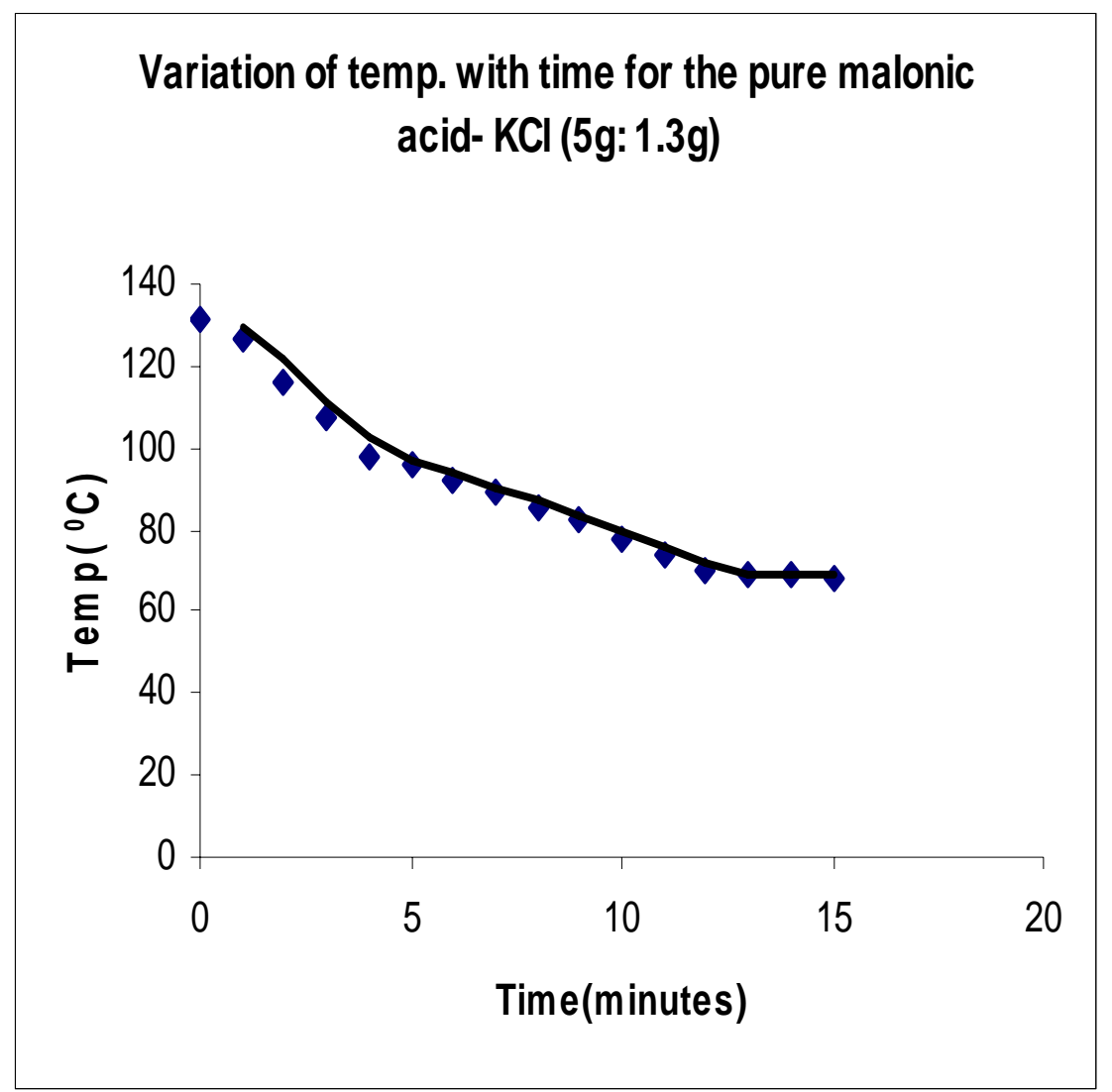

Figure 6: Variation of Temperature with Time for the Pure Malonic Acig - KCl (5g:1.3g)

\section{CONCLUSION}

Based on the results obtained in this study, it can be concluded that addition of non-volatile solute

\section{REFERENCE}

Alberty, D. (1979): Physical Chemistry 5the edition, Johniviley and Jou pp $118-119$

Atkins, P. N. (1997). Physical Chemistry 6the edition WH Freeman and company pp $142-143$.

Finar, I. L. (1973): Organic Chemistry $5^{\text {th }}$ edition, $1: 448-449$

Mc - Graw, Hill (1974): Dictionary of scientific and Technical Term, MC Graw Hill Inc pp 897, 1155. decreases the freezing point of a solvent and the depression is directly proportional to the amount of non-volatile solute.

Micheal, F. (1987). Chemistry in Action. Macmillan Education Ltd (London) p 228.

Clugston M.G. and Atkins P.W. (1982). Principles of Physical Chemistry. Pp 105.

Morrison R.T. and Robert T...M. (2000). Organic Chemistry, $6^{\text {th }}$ edition, U.S.A. Pp 743.

Todorovi, Z., Pol, P., Dgordjevi, D. and Autoni Jevi S. (2001). Lead Distribution in water and its Association with sediment constituents of the Baije Lake (Leskovae, Yugoslavia). J. Serb. Chem. Soc. 66 (1): 697 - 708. 